\title{
Assessment of Nano-leakage for Three Adhesive Systems: An In Vitro Study
}

\section{Ibrahim D. Basha*1}

Codex : 02/2021/10

Aadj@azhar.edu.eg

\section{KEYWORDS}

Adhesives, Resin composites, Bonding; Clearfil, G-bond, Adper

1. Department of Operative Dentistry, Faculty of Dental Medicine, (Cairo-Boys), Al-Azhar University, Egypt

* Corresponding Author e-mail: IbrahimBasha.209@azhar.edu.eg

\begin{abstract}
Aim: This research evaluates the nanoleakage in Adper single bond 2, Clearfil SE BOND 2, and G-bond plus adhesive systems . Materials and Methods: Forty-five freshly extracted human maxillary premolar were selected for measuring their nanoleakage. The selected teeth were divided into three main groups according to adhesive systems $(n=15)$. Group I: etch and rinse system (Adper single bond 2), group II: self-etch two-step system (Clearfil SE BOND 2), group III: self-etch all in one system (G-bond Plus). Each group was divided into 3 subgroups according to storage time $(n=5)$ (one day, one month, six months. MOD cavity was prepared with 2.5 depth and $2 \mathrm{~mm}$ width and restored with restorative materials before nanoleakage at dentin adhesive interface is measured with a scanning electron microscope . Results: The result of this study revealed that Adper single bond 2 is inferior to G- bond plus then Clearfil SE BOND 2 . Conclusions: Clearfil SE BOND 2 seems to be an efficient adhesive. The storage in water for long periods has a highly significant adverse effect on the nanoleakage.
\end{abstract}

\section{INTRODUCTION}

Dental adhesives that bond composite resins to the dental enamel and dentin are designed to provide immediate favorable results in the retention and sealing of the bonded interface ${ }^{[1,2]}$. The functionality of dental restorations depends on several variables, including the quality of bonding of these restorations to the tooth structure ${ }^{[3]}$. With the improvement in dentin bonding systems, both the enamel and dentin restoration interface have attained a gap-free margin. However, another type of leakage, nanoleakage, has been detected using a scanning electron microscope (SEM). This has occurred despite gap-free margins in dentin bonded preparations due to the acid etching procedure, which allows oral and pulpal liquids to infiltrate the interface ${ }^{[4]}$. Nanoleakage denotes the spread of small ions or molecules in the hybrid layer without gap formation through nanometer-sized spaces of approximately 
$0.02 \mu \mathrm{m}$ nanoleakage initiates at the hybrid layer, in which resin monomers interface directly with decalcified dentin and spreads laterally over time ${ }^{[5]}$. Dentin bonding can be augmented by either etchand-rinse (ER) or self-etch (SE) adhesives.

Nevertheless, creating a path for adhesive resin infiltration into the collagenous matrix remains challenging. In ER bonding systems, phosphoric acid (pH 0.3-0.4) mainly serves this purpose, which levigates the minerals to a depth of 5-10 $\mu \mathrm{m}$, resulting in a highly porous dentin collagen network suspended in water. Then,resin monomers infiltrate the collagen network ${ }^{[6]}$. Acidic resin monomers in SE systems can etch and prime the dental substrate at the same time ${ }^{[7]}$. Therefore, we comparedseveral major adhesive systems to considerhow to improve performance in clinical practice without jeopardizing bonding efficacy.

Due to the technique, complexity, and sensitivity of restoring teeth with resin composites, advances in adhesive systems aim to simplify the clinical application and offer a convincing, patient-friendly advantage ${ }^{[8]}$.

Self-etch adhesives are applied clinically in a single step or two steps. etching, priming, and bonding agents are combined in all-in-one adhesives. In contrast,two-step self-etch adhesives contain a hydrophilic self-etching primer, which leaves after evaporation a layer of hydrophobic bonding agent to seals the etched tooth surface ${ }^{[8]}$.

The solvents dissolve the monomers, preserve the collagen network's expanded state, and give the monomers the chance to fill the spaces within and around the collagen fibrils. The polymerization of these monomers, when activated by the curing light, gives a polymer-collagen biocomposite ${ }^{[6,7]}$. This research evaluates the nanoleakage in AdperSingle Bond 2, Clearfil SE BOND 2, and G-BOND PLUS adhesive systems.

\section{MATERIALSAND METHODS}

\section{Preparation of Specimens for Nanoleakage}

The selected teeth were placed $3 \mathrm{~mm}$ below the cementoenamel junction in an acrylic mold of 15$\mathrm{mm}$ diameter and $20-\mathrm{mm}$ height. We prepared the cavity design with our pre-fabricated device (Figure 1), composed of a stainlesssteel base with a stainless steel column and fitting clamp. The stainlesssteel column was graduated and consisted of twoparts. We used the first part (the fitting screw) to fix the handpiece in a position parallel to the tooth block, while the second part (the adjusting screw) allowed movement of the handpiece upward and downward to standardize the depth of the cavity. We fitted the tooth block with a fitting clamp. We used the adjusting clamp to allow adjustment of the tooth block to a position perpendicular to the column.

First, we connected the handpiece to the air nodule and adjusted the handpiece with the adjusting screw to a position in which the fissure bur rested in the middle of the premolar's central groove. We then used the adjusting clampto move the tooth block in a lateral direction, away from the fissure bur. We moved the handpiece $2 \mathrm{~mm}$ on the graduated column. Weused the foot control of the handpiece before moving the tooth block toward the rotated fissure bur with the adjusting clamp. This allowed us to cut the tooth from one proximal surface to another, doing a MOD cavity $2 \mathrm{~mm}$ deep and $2 \mathrm{~mm}$ wide. We repeated these procedures to make cavities with depthsof $2.5 \mathrm{~mm}$ and $3 \mathrm{~mm}$. We kept the fissure bur at a high cutting efficiency to apply minimal pressure when cutting the tooth structure.

The benefits of using Basha's device are the standardization of cavity dimensions and depth to give an instant reading of data related to nanoleakage; this was the only device we could design to make standardized cavities within the locality rule.

\section{Bonding and restorative application}

Each type of resin composite and its bonding procedure followedthe respective manufacturer's 
instructions. We applied the resin composites of all groups by the incremental technique, and the matrix band was fixed by a matrix holder. We cured the composite resins according to the curing system of each group. The composites were packed by Teflon condenser into the prepared cavity. The composite resin was cured by using LED light-curing unit (normal curing mode) for 40 seconds.

\section{Storage of specimens}

After restoring all specimens, we stored them in a special container containing $20 \mathrm{~mL}$ of distilled water at $37^{\circ} \mathrm{C}$ in an incubator with $100 \%$ humidity at different storage timings: 1 day, 1 month, and 6 months.

\section{Nanoleakage Measurements}

\section{Sealing of teeth:}

The experimented teeth were coated with a twolayer protective nail varnish, which is acid-resistant, except for $1 \mathrm{~mm}^{2}$ around the margin of the restorations. The nail varnish was set to dry for 2 hours. We used a greenstick compound to seal the varnish to prevent dye penetration through the apical foramen.

\section{Silver nitrate preparation:}

After immersing the specimens in an aqueous solution of $50 \%$ weight of ammoniacal silver nitrate (pH 9.5) for 24 hours, an 8-hour immersion in a photo-developing solution followed to reduce diamine silver ions to metallic silver grains. The specimens were retrieved from the photo-developing solution and washed in running water for 60 seconds before allowing them to air-dry at room temperature.

\section{Sectioning of teeth:}

Longitudinal sectioning of the studied teeth was made in a buccolingual direction just in the middle of the restoration using a diamond disk. The cutting was operationalized at low speed with water coolant.

\section{SEM examination:}

Finally, we used one tooth from each group (random specimen) in the nanoleakage study at the end of storage time (1 day, 1 month, and 6 months, respectively) for SEMexamination to evaluate the resin-dentin interfaces. The cut surfaces of each half were ground and polished to a high gloss with wet silicon carbide sandpaper to avoid deterioration of the SEM's electron beam. Then, the specimens were decalcified with $5 \%$ hydrochloric acid for 45 seconds to remove the smear layer and expose the acid-resistant hybrid layer. We then immersed the specimens in $1 \% \mathrm{NaOCl}$ for 10 minutes to remove any unpolymerized resin, followed by 30 minutes of immersion in a dapping dish containing distilled water to remove any residue of $\mathrm{NaOCl}$. We fixed the specimens with silver adhesive on the SEM specimen holder and sputter-coated them with a thin film of gold $300 \AA$ under vacuum to render the specimens' surfaces electrically conductive.

\section{RESULTS}

We calculated the descriptive statistics, Data were then checked for normality using Kolmogorov-Smirnov and Shapiro-Wilk tests to verify they follow a normal distribution. We used one-way ANOVA test and Tukey's posthoc test to compare the variance between variables. The statistical significance was set at a p-value of 0.05.

Following are the effects of different variables: adhesive systems [AdperSingle Bond 2 (AB), Clearfil SE BOND 2 (CB) and G Premio Bond (GB)]; and storage time [1 day (T1), 1 month (T2), and 6 months (T3)] on nanoleakage.

\section{Clearfil SE BOND 2 Groups}

On the one hand, the difference between $(\mathrm{AB} / \mathrm{T} 3)$ was statistically significant, and so were the differences between $(\mathrm{AB} / \mathrm{T} 1)$ and $(\mathrm{AB} / \mathrm{T} 2)$. $(p=.004$ and 0.01 , respectively). No statistically significant difference was found between $(\mathrm{AB} / \mathrm{T} 1)$ and $(\mathrm{AB} / \mathrm{T} 2)$ where $(p=.07)$ 


\section{G-BONDPLUSGroups versusClearfil SE BOND 2 Groups}

On the one hand, the difference between $\mathrm{CB}$ and $\mathrm{T} 1$ was statistically significant $(p<.00)$, and so were the differences between CB T2 and CB /T3 ( $p=.03$ and .001 , respectively).The differences between $\mathrm{CB}$ and $\mathrm{T} 2$ and between $\mathrm{CB}$ and $\mathrm{T} 3$ were statistically significant ( $p=.001$ and .000 , respectively).

\section{AdperSingle Bond 2 Groups}

A statistically significant difference was found between $(\mathrm{GB} / \mathrm{T} 1)$ on the one hand. There was a statistically significant difference between each of GB /T2 and GB /T3, on the other hand $(p<.001)$. Also, a statistically significant difference was found between $\mathrm{AB} / \mathrm{T} 2$ and GB /T3 where $(p=.007)$.

Table 1. Parameters of the proposed methodology.

\begin{tabular}{|c|c|c|c|}
\hline Product name & Category & Composition & Manufacturer (patch number) \\
\hline $\begin{array}{l}\text { Adper single } \\
\text { bond } 2\end{array}$ & $\begin{array}{l}\text { Two-step etch \& } \\
\text { rinse adhesive }\end{array}$ & $\begin{array}{l}\text { BisGMA, HEMA,dimethacrylates, ethanol, water, } \\
\text { photoinitiator system, methacrylate functional co- } \\
\text { polymer of polyacrylic and polyitaconic acids, } 5 \mathrm{~nm} \\
\text { silica particles. }\end{array}$ & $\begin{array}{l}\text { 3M ESPE Dental Product St. } \\
\text { Paul, MN, USA } \\
(51202)\end{array}$ \\
\hline $\begin{array}{l}\text { Clearfil SE } \\
\text { bond2 }\end{array}$ & $\begin{array}{l}\text { Two step self- } \\
\text { etch adhesive }\end{array}$ & $\begin{array}{l}\text { 1- Primer: water, MDP, HEMA, Camphorquinone, } \\
\text { Hydrophilic dimethacrylate. } \\
\text { 2- Adhesive: MDP, BisGMA, HEMA, } \\
\text { Camphorquinone, Hydrophobic dimethacrylate, } \\
\text { N,N-diethanol, p-toluidine bond, colloidal silica. }\end{array}$ & $\begin{array}{l}\text { KuraryNortake Dental Inc. } \\
\text { Okayama-Japan } \\
5 \text { V0016 }\end{array}$ \\
\hline G-bond plus & $\begin{array}{l}\text { All in one self- } \\
\text { etch adhesive }\end{array}$ & $\begin{array}{l}\text { Acetone, dimethacrylate, triethylenedimethacrylate } \\
\text { (TEGDMA), 4-methacryloyloxyethyl trimellitic } \\
\text { acid (4-MET), phosphoric acid ester monomer, sili- } \\
\text { con dioxide, photo initiator }\end{array}$ & $\begin{array}{l}\text { GC corporation Tokyo-Japan } \\
(1102221)\end{array}$ \\
\hline
\end{tabular}

Table 2. Mean and standard deviation values for nanoleakage measures.

\begin{tabular}{lllll}
\hline $\begin{array}{l}\text { Group } \\
\text { Time }\end{array}$ & $\begin{array}{l}\text { Clearfil SE }(\mathbf{C B}) \\
\text { Mean } \pm \text { SD }\end{array}$ & $\begin{array}{l}\text { G-bond plus }(\mathbf{G B}) \\
\text { Mean } \pm \text { SD }\end{array}$ & $\begin{array}{l}\text { Adper single }(\mathrm{AB}) \\
\text { Mean } \pm \text { SD }\end{array}$ & $\boldsymbol{p}$-value \\
\hline 1Day (T1) & $0.00 \pm 0.00$ & $0.00 \pm 0.00$ & $0.00 \pm 0.00$ & $>0.05$ \\
\hline 1-Month (T2) & $1.51 \pm 0.4$ & $2.85 \pm 0.3$ & $4.37 \pm 0.7$ & $<0.05^{*}$ \\
\hline 6-Months (T3) & $3.97 \pm 0.7$ & $5.97 \pm 0.2$ & $7.97 \pm 0.3$ & $<0.05^{*}$ \\
\hline $\boldsymbol{p}$-value & $0.05^{*}$ & $<0.05^{*}$ & $<0.05^{*}$ & \\
\hline
\end{tabular}

(*) significant ( $p$-value $<0.05)$

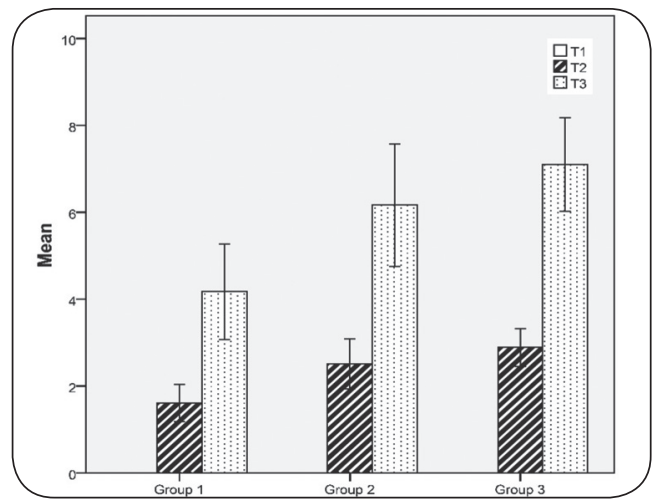

Fig. (1) Bar chart representing nanoleakage with different variables.

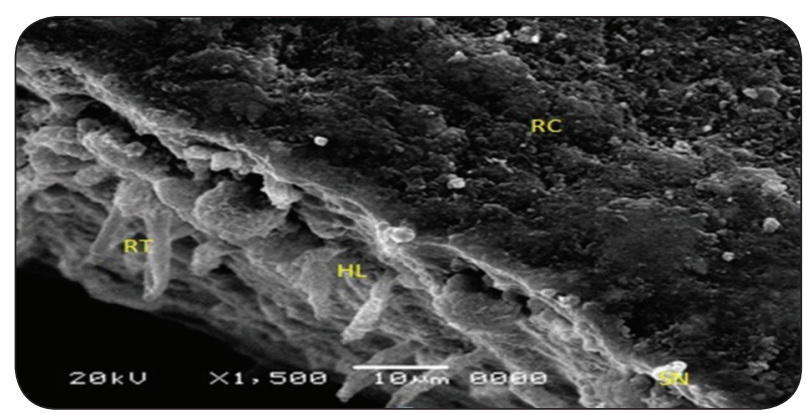

Fig. (2) SEM for the resin dentin interface $(\times 1500)$ using Clearfil SE BOND 2 adhesives after six months of storage. HL: Hybrid layer, SN: Silver nitrate, RT: Resin tags, RC: Resin composite. 


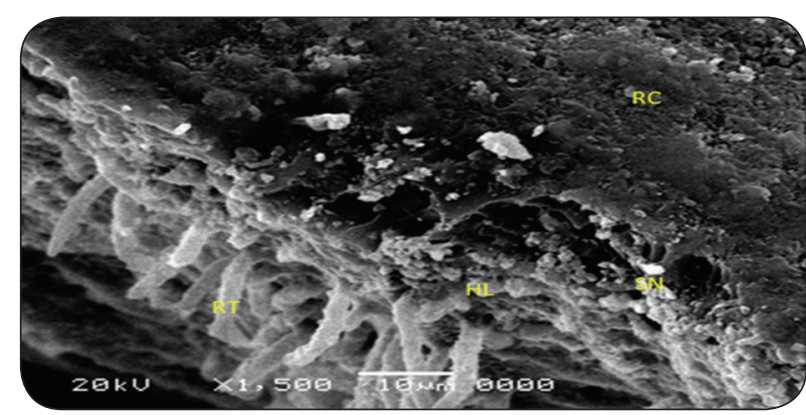

Fig. (3) SEM for the resin dentin interface $(\times 1500)$ using G-bond plus adhesive after six months of storage. HL: Hybrid layer, SN: Silver nitrate, RT: Resin tags, RC: Resin composite.

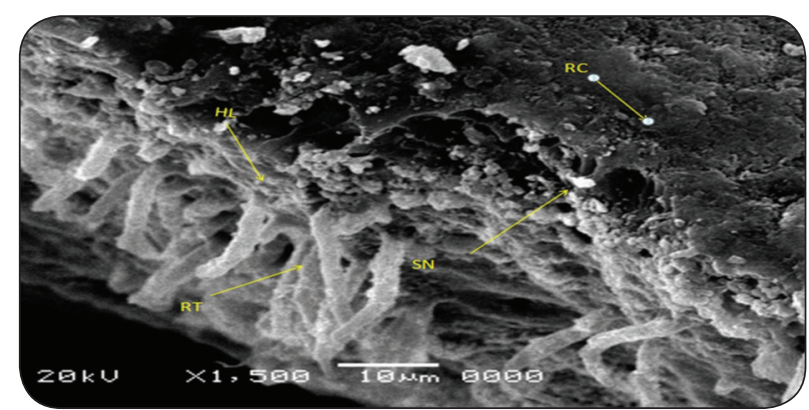

Fig. (3) SEM for the resin dentin interface $(\times 1500)$ using G-bond plus adhesive after six months of storage. HL: Hybrid layer, SN: Silver nitrate, RT: Resin tags, RC: Resin composite.

\section{DISCUSSION}

The resin impregnation techniques, use of a hydrophobic coating of non-solvated resin, prolonged curing time, and inhibiting the intrinsic collagenolytic activity of human dentin have proven effective in improving the adhesion ${ }^{[2]}$. The crucial indicator of the sealing of restorative materials is the nanoleakage. Hybridization results from molecular-level interaction between the resin and the demineralized collagen fibrils network are considered the key phenomenon in bonding resin composite restorations to dentin ${ }^{[9,11]}$.

ER and SE are two major etching techniques. ER etchant influences nanoleakage as ER employs a 30\%-40\% phosphoric acid gel that induces selective solubilization of hydroxyapatite crystals and exposes collagen fibrils.The two- or three-step ER adhesives weaken the bond strengths and the hybridlayer. In contrast, SE adhesives produce a hybridized complex comprising the residual smear layer and a thin, partially demineralized, dentin collagen matrix.

Our results demonstrated different nanoleakage patterns in all bonding systems tested by studying the ultrastructural characteristics of three adhesive systems. However, silver ion accumulations were often noted at the base of the hybrid layer for all materials, which was consistent with Lopes et al. ${ }^{[12]}$. The data in Table 2 revealed that the two-step selfetch adhesive (Clearfil SE BOND 2) exhibited the smallest amount of nanoleakage, followed by all-inone self-etch adhesive (G-BOND PLUS). The ER adhesive (AdperSingle Bond 2) demonstrated the greatest leakage.Perhaps the two-step application of Clearfil SE BOND 2 is an advantageous adhesive system as it etches away most of the smear layer without removing the smear plugs or peritubular dentin. It also demineralizes the intertubular dentin. Clearfil SE adhesive's hydrophobic nature manifested as a lack of water diffusion exhibiting little nanoleakage compared to other adhesive systems ${ }^{[8]}$.

The relative minimal nanoleakage observed with Clearfil SE BOND could be attributed to its 10-methacryloyloxydecyl dihydrogen phosphate monomer (10-MDP), which encompasses dihydrogen phosphate group that dissociates in water to form two protons and cause the solicited effect ${ }^{[13]}$.

This finding contradicts Ferreira et al. ${ }^{[14]}$, who found that the Clearfil SE primer's water content reacts with the phosphorylated methacrylate to generate the hydrogen ions required for the demineralization of dentin. In contrast, uncured resin monomers from the adhesive induce apressure gradient from the dentinal tubules, which causes bond degradation with aging.

Some remnant dentin appetites and amorphous calcium phosphates may induce a re-precipitation in the bonded interfaces of non-rinsing adhesives may dissolve after immersion in conventional, acidic 
silver nitrate (pH3.4). The resultant artifactual microporositiescan render false-positive results ${ }^{[15]}$.

AdperSingle Bond 2 adhesive system (ER adhesive) showed the largest amount of nanoleakage. This may be explained by the fact that using contemporary ER adhesives involves a degree of technique sensitivity that may compromise their bonding efficacy and marginal seal. Dry bonding averts proper resin infiltration within the demineralized collagen network. On the contrary, inter-peptide or peptide-proteoglycan hydrogen bonding,which develops during air-drying, initiatesa remarkable collapse of interfibrillar spaces in the demineralized matrix. The improper solvent evaporation results in dilution, inferior polymerization of the resin components. Recent types of etching and rinse adhesives comprise high concentrations of water or organic solvent. For the light-cured adhesive, entrapment of residual water or solvents within hybrid or resin layer may become pathways water movement within these layers, which makes the resin-dentin interfaces permeable. The subsequent susceptibility to degradation via resin hydrolysis and collagen degrading enzymes is conspicuous [16]. This finding is consistent with previous studies $[14,16]$. They concluded that incomplete resin penetration in the hybrid layer or incomplete solvent evaporation permits nanoleakage to occur.

G-BOND PLUS adhesive (one-step self-etch adhesive) showed the amount of nanoleakage more than Clearfil SE BOND 2 because one-step adhesives are more acidic and contain a large hydrophilic component that could not be completely polymerized during the light-curing period ${ }^{[11]}$. This finding agrees with previous studies, ${ }^{[12-18]}$. which concluded that the increase in the acidity of the adhesive solution requires elevating the contents of acidic monomers and water-increasing hydrophilicity and water sorption. Consequently, hydrolytic stability decreases.

The formulation of G-BOND PLUS adhesiveembeds acetone with water to repel excessive water moleculesout of the dentin matrix. With the potential difference between the evaporation rate of both liquids after applying the adhesive system, water trees remain tagged, inducing some osmotic water movement through the dentinal tubules and the hybrid layer. Any delay in the time-dependent placing of resin composites over the cured adhesive layer permits some water permeation over the cured adhesive layer. Theseparation of HEMA-free adhesive with after producing droplets throughout the adhesive layer causes a degree of nanoleakage. ${ }^{[19]}$. Imperfect durability of resin-dentin bonds is the usual cost that is concomitant with saving procedural time and effort, especially with dentin bonding ${ }^{[9]}$. Insights about investigating the nanoleakage and microleakage are under investigation of several methodological approaches. Yet, optical coherence tomography seems to be a game-changer with standardizing the retrieved results ${ }^{[20,21]}$.

\section{CONCLUSION}

This paper aimed to compare the nanoleakage of the AdperSingle Bond 2, Clearfil SE BOND 2, and G-BOND PLUS adhesive systems in a sample of freshly extracted human maxillary premolars. The results demonstrated the superiority of Clearfil SE BOND 2. Our results suggested that the storage in water for long periods has a highly significant adverse effect on the nanoleakage.

Our results demonstrated different nanoleakage patterns in all bonding systems tested by studying the ultrastructural characteristics of three adhesive systems. Our results suggested that the storage of samples in water for long periods has a highly significant adverse effect on nanoleakage. We also designed Basha's customized device for standardizing the preparation procedures. The use of retrievable methods can fill the gap frequently encountered in previous studies that did not pay enough attention to non-standard preparation procedures.

Occlusal mastication forces, and cyclic expansion and contraction stresses affect the bonding du- 
rability, including nanoleakage and so are repetitive expansion and contraction stresses due to thermal changes in the oral cavity. Because the oral cavity is a harsh environment, in-vitro findings are only suggestive given the lack of their standardized methods. Therefore, the need for conducting long-term clinical studies to examine the impact of time and chemical structure on bonded interfaces cannot be emphasized. Computational mapping and integration of retrieved findings on bonding efficiency are also encouraged.

\section{Funding Sources: None}

\section{Conflict of interest: None}

\section{REFERENCES}

1. Van Landuyt KL, Snauwaert J, De Munck J, Peumans M, Yoshida Y, Poitevin A, Coutinho E et al. Systematic review of the chemical composition of contemporary dental adhesives. Biomaterials. 2007 Sep;28(26):3757-85.

2. Breschi L, Mazzoni A, Ruggeri A, Cadenaro M, Di Lenarda R, De Stefano Dorigo E. Dental adhesion review: aging and stability of the bonded interface. Dent Mater. 2008;24(1):90-101.

3. Li H, Burrow M, Tyas M. Nanoleakage patterns of four dentin bonding systems. Dent Mater 2000; 18: 48-56.

4. Sano H, Takatsu T, Ciucchi B, Horner JA, Matthews WG and Pashly DH. Nanoleakage: leakage within the hybrid layer. Oper Dent 1995; 20: 18-25.

5. Carvalho RM, Tay F, Sano H, Yoshiyama M and Pashley DH. Long-term mechanical properties of EDTAdemineralized dentin matrix. J Adhes Dent 2000; 2:193-9.

6. Pashely DH et al . State of the art etch and rinse adhesives. Dent Mater 2011; 27:1-16.

7. Van Meerbeek B. et al .state of art self-etch adhesives. Dent Mater 2011;27: 17-28.

8. Halabi S, Matsui N, Nikaido T, Burrow MF, Tagami J. Effect of office bleaching on enamel bonding performance. J Adhes Dent 2019;21(2):167-177.

9. Yoshimine N, Shimada Y, Tagami J, Sadr A. Interfacial adaptation of composite restorations before and after light curing: Effects of adhesive and filling technique. J Adhes Dent 2015;17(4):329-336.
10. Akalla S, Sujeer R, Thomas T. Nanoleakage evaluation of silorane based, nanohybrid, and giomer composites. J Dent 2014; 13:62-4.

11. Duarte S Jr, Phark JH, Varjao FM, Sadan A. Nanoleakage, ultramorphological characteristics, and microtensile bond strengths of a new low-shrinkage composite to dentin after artificial aging. Dent Mater 2009; 25:589-600.

12. Lopes MB, Moraes RR, Gonini-Junior A, Piva E. Impact of curing protocol on the selected properties of a model bis-GMA/TEGDMA dental resin composite. Biomed Mater. 2009; 4: 025014.

13. Kaczor K, Gerula-Szymańska A, Smektała T, Safranow K, Lewusz K, Nowicka A. Effects of different etching modes on the nanoleakage of universal adhesives: A systematic review and meta-analysis. J Esthetic Restorative Dent 2018;30(4):287-98

14. Ferreira JC, Pires PT, Azevedo AF, Oliveira SA, Melo PR and Silva MJ. Influence and composition of etch-and-rinse and self-etch adhesive systems on the nanoleakage within the hybrid layer. J Contemp Dent Pract 2013; 14:691-9.

15. Torkabadi S, Nakajima M, Ikeda M, Foxton RM, Tagami J. Bonding durability of HEMA-free and HEMA-containing one-step adhesives to dentine surrounded by bonded enamel. J Dent. 2008 Jan;36(1):80-6. doi: 10.1016/j.jdent.2007.11.001.

16. Yuan Y, Shimada Y, Ichinose S, Tagami J. Qualitative analysis of adhesive interface nanoleakage using FE-SEM/ EDS. Dent Mater 2007;23:561-9.

17. Tay FR, Pashley HD, Yoshiyama M. Two modes of nanoleakage expression in single step adhesive. J Dent 2002; 81:471-6.

18. Tay FR, King NM, Chan KM, Pashley DH. How can nanoleakage occur in self-etching adhesive systems that demineralize and infiltrate simultaneously? J Adhes Dent. 2002;4(4):255-69.

19. Tay FR, Pashley DH, Yoshiyama M. Two modes of nanoleakage expression in single-step adhesives.J Dent Res. 2002 Jul;81(7):472-6. doi: 10.1177/154405910208100708.

20. El-Basha E. Assessment of composite leakage using optical coherence tomography: A systematic review. Adv Clin Exp Dent. 2020;1(1):19-32. Doi: 10.21608/ ACED.2020.150766.

21. Reis AF, Giannini M, Pereira PN. Long term analysis of the nanoleakage patterns in resin dentine interfaces produced by different bonding strategies. Dent Mater2007; 23: $1164-72$. 
مجلة أسيوط لطب الأسنان
النشر الرسمي لكلية طب الأسنان جامعة الأزهر أسيوط الكاية

مصر

\title{
تقييم التسرب النانوn لثلاثة انظمه لاصقه: دراسة خارج الجسم الحمب النوم
}

* إبراهيم الدشوقى باشا

\author{
1. قسـم العلاج التحفظي، كلية طب الاسنان، (بنين - القاهرة)، جامعة الأزهر، مصر

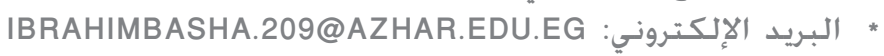

(الملخص:

الهـدف: يقوم هذا البحث بتقييم التسرب النانوي في ثلاثة أنظمة لاصقة.

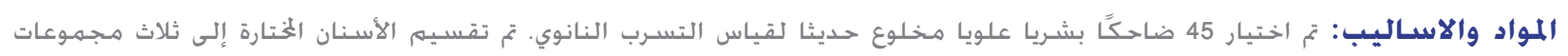

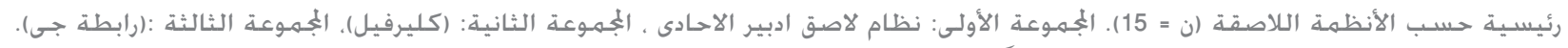

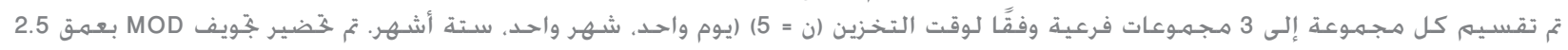

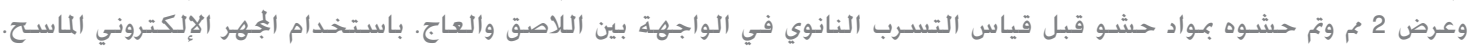
النتائج: أظهرت نتيجة هذه الدراسة أن لاصق ادبير الأحادي أقل كفاءة من رابطة جى بالإضافة إلى كليرفيل الحخلاصة: يبدو أن كليرفيل مادة لاصقة فعالة. وأن التخزين في الماء لفترات طويلة له تأثير ضار بالغ الوضوح على التسرب النانوي. الكلمات المفتاحية: اللاصق. مركبات راتنجيه، رابطه, كليرفيل، رابطة جى .لاصق ادبير الاحادى 